\title{
Impactos da alteração no albedo das superfícies no microclima e nos níveis de conforto térmico de pedestres em cânions urbanos
}

\author{
Impacts of changes in surface albedo on microclimate and \\ pedestrian thermal comfort levels in urban canyons
}

\section{Eduardo Leite Krüger \\ Dominique Elena Giordano Gonzalez}

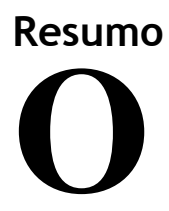

albedo de superfícies urbanas está diretamente relacionado à sua capacidade de absorver energia ou refleti-la para as superfícies adjacentes, influindo sobre as condições microclimáticas e de conforto térmico em nível do pedestre no espaço aberto. Este artigo analisa a influência de alterações do albedo de revestimentos de superfície sobre a temperatura do ar de um cânion urbano e sobre o grau de conforto térmico em nível do pedestre, em cidades de médio porte localizadas nas oito zonas bioclimáticas brasileiras. Para isso se utiliza o modelo preditivo CAT, do inglês canyon air temperature, em conjunto com o índice de conforto ITS. Os resultados mostraram que o impacto do aumento do valor do albedo das superfícies urbanas sobre a temperatura do ar é pequeno e que, de forma geral, o aumento do albedo superficial tende a piorar os níveis de conforto térmico para o pedestre. Assim, o uso de albedos altos não deve ser prescrito a todas as superfícies de cânions urbanos indiscriminadamente, exigindo avaliação das condições locais de modo a identificar as superfícies em que haja suficiente exposição solar para que o uso de albedos altos seja efetivo, de modo que isso não implique em prejuízo significativo para o conforto térmico de pedestres.

Palavras-chaves: Albedo. Cânion urbano. Conforto térmico. Microclima.

Eduardo Leite Krüger Universidade Tecnológica Federal do

Curitiba - PR - Brasil

\section{Dominique Elena Giordano \\ Gonzalez}

Instituto Federal de Educação,

Ciência e Tecnologia do Paraná Curitiba - PR - Brasil

Recebido em 06/11/15

Aceito em 23/03/16

\section{Abstract}

Urban surface albedo is directly related to their ability to absorb energy or reflecting it to the adjacent surfaces, affecting the microclimatic conditions and thermal comfort in the pedestrian level in open space. The aim of this paper is to analyse the influence of changes in albedo of urban surfaces on canyon air temperature and on pedestrian thermal comfort, for mid-sized cities located in the eight Brazilian bioclimatic zones. For this purpose the predictive model canyon air temperature (CAT) and the comfort index ITS have been used. Results showed that impact of changing from low to high surface albedo is negligible for air temperatures whereas an increase of surface albedo tends to worsen thermal comfort conditions at the pedestrian level. Therefore, the use of high albedo should not be prescribed to canyon surfaces indiscriminately, as it requires an assessment of local conditions in order to identify which surfaces have enough solar exposure for an effective use of higher albedo, without negatively affecting pedestrian thermal comfort.

Keywords: Albedo. Urban canyon. Thermal comfort. Microclimate. 


\section{Introdução}

O fenômeno de ilha de calor urbano (ICU) é caracterizado por diferenças de temperatura entre as áreas urbana e rural. Esse fenômeno é resultado da superposição de diversos fatores introduzidos no processo de urbanização. Essencialmente, podese dizer que a causa da ICU é a interferência da cidade e seus processos no balanço de energia da superfície terrestre, especialmente o aumento da absorção de energia solar, na forma de calor, sobre a área urbana se comparada à área rural, e também maior geração de calor antropogênico (OKE, 2002).

Diversos estudos abordam estratégias para a mitigação dos efeitos da ICU e, entre essas estratégias, inclui-se o uso extensivo de materiais de alto albedo (ou de alta refletância). Tais materiais, ao refletirem uma maior parcela da radiação solar incidente, absorvem menos energia, apresentando reduções na temperatura superficial. Há referências que incentivam o uso desses materiais não apenas em coberturas (JACOBSON; TEN HOEVE, 2012), mas também em pavimentos (CARNIELO; ZINZI, 2013). O objetivo é que, com a redução da temperatura de superfície, haja menor aquecimento do ar no plano do pedestre, consequentemente reduzindo-se o efeito de ICU.

No entanto, Emmanuel e Fernando (2007) sugerem que a temperatura do ar, isoladamente, não é um bom parâmetro para avaliar os benefícios de estratégias de mitigação da ICU, e que, em vez disso, deve ser usada de forma combinada com índices de conforto humano. Alguns estudos têm demonstrado que, embora o aumento do albedo possa reduzir as temperaturas de superfície e do ar, maior quantidade de radiação refletida incidirá sobre o pedestre, o que pode aumentar seu desconforto térmico (ERELL et al., 2014). Da mesma forma, a radiação refletida incidirá sobre eventuais janelas voltadas ao cânion, aumentando a carga térmica nos ambientes internos e resultando em maior consumo energético (YAGHOOBIAN; KLEISSL, 2012; SAILOR et al., 2012).

O estudo de Taha et al. (1988) indicou efeitos do albedo no consumo energético de edifícios, e destes na ICU. Tais autores simularam, com base em três modelos numéricos, os efeitos de alterações de albedo nas cargas de resfriamento e aquecimento de uma edificação-padrão localizada em Sacramento, Califórnia, escolhida em razão de esta ser uma cidade quente e com grandes áreas vegetadas. Dois efeitos foram analisados: alteração do valor do albedo nas fachadas da própria edificação para a qual se avalia o consumo em climatização artificial (efeito direto) e alterações globais do albedo das superfícies urbanas do entorno (efeito indireto) no consumo em climatização artificial daquela edificação. $\mathrm{O}$ efeito indireto mostrou resultados significativos na redução da carga para resfriamento da edificação, com baixo prejuízo em termos de aumento da carga de aquecimento. Uma possível limitação da pesquisa é que alterações nos dados microclimáticos usados na estimativa de carga térmica para manutenção do conforto na edificação consideraram apenas a componente temperatura do ar para fins de comparação do efeito do albedo.

Estudos recentes têm sido mais cautelosos em relação à aplicação do albedo. Synnefa, Santamouris e Livada (2006), apesar de comprovarem em seu estudo a efetiva redução de temperatura superficial resultante de coberturas de alto albedo, ressaltam em suas conclusões que, antes da aplicação de tais coberturas em determinado local, um amplo estudo deveria ser realizado de modo a avaliar o impacto dessas superfícies no microclima ao seu redor, de forma a evitar consequências indesejáveis como aumento do ofuscamento e de radiação solar refletida.

O estudo de Yaghoobian e Kleissl (2012) mostra que o aumento do albedo pode levar a um aumento da carga térmica de refrigeração interna em edificações, enquanto a carga térmica anual de aquecimento pode não se mostrar sensível a esse parâmetro. O estudo foi realizado para a cidade quente e seca de Phoenix, Arizona, considerando um edifício de quatro pavimentos com uma relação entre área de abertura e área de fachada (windowto-wall ratio ou WWR) de aproximadamente $50 \%$. As simulações de consumo energético acusaram aumento significativo da carga de refrigeração anual para aquela localidade, para um aumento do albedo da pavimentação do entorno de 0,1 para 0,5. Para tanto, Yaghoobian e Kleissl (2012) realizaram simulações do microclima de modo a prever os efeitos de mudanças no albedo superficial e simulações termoenergéticas paramétricas da edificação, considerando: mudanças no albedo, WWR, razões entre altura (H) e largura (W) da via, etc. O aumento da carga térmica de refrigeração deve-se a um desproporcional aumento nos fluxos térmicos radiantes relativamente a uma redução na temperatura do ar no dossel urbano, e mostrou, além disso, que o impacto de mudanças na geometria do cânion sobre a temperatura ambiente no dossel é maior que o de alterações do albedo.

$\mathrm{O}$ estudo de Erell et al. (2014) mostra que o aumento do albedo piorou as condições de conforto térmico no plano do pedestre nos cenários 
por eles estudados, utilizando as mesmas ferramentas do presente estudo: o modelo CAT e o índice ITS (da sigla em inglês index of thermal stress), descritos mais adiante. Tais autores consideraram quatro situações climáticas bem diferenciadas nas simulações: Eilat, em Israel; Göteborg, na Suécia; Singapura; e Adelaide, na Austrália. Verificaram que a influência de alterações do albedo de superfície, de um valor de 0,2 para 0,7 , na temperatura do ar foi pouco significativa, atingindo um máximo de $0,4{ }^{\circ} \mathrm{C}$ de redução em torno do pico de radiação solar em um cânion de razão $\mathrm{H} / \mathrm{W}=1$ (como o simulado nesta pesquisa, ver seção Metodologia), para Adelaide. No entanto, fazendo o particionamento dos fluxos de energia para o pedestre, os autores notaram, para valores mais altos de albedo superficial, aumento do fluxo térmico para o pedestre, com prejuízos na sensação de conforto predita.

Shashua-Bar, Tsiros e Hoffman (2012) investigaram o efeito de resfriamento e impactos no conforto térmico no nível do pedestre com o aumento do albedo das fachadas de um cânion urbano. $\mathrm{O}$ estudo foi realizado para condições de calor em Atenas, Grécia, por meio de um modelo analítico de clima urbano (Green-CTTC), cujos resultados foram adotados para o cálculo do índice de conforto PET, do inglês physiological equivalent temperature. $\mathrm{Na}$ simulação de modificações do albedo, consideraram-se apenas alterações nos valores das fachadas de um cânion urbano relativamente raso $(\mathrm{H} / \mathrm{W}=0,42)$, de 0,4 para 0,7 . O resfriamento na temperatura do ar resultante do aumento do albedo de superfície das fachadas foi pequeno, da ordem de $0,7^{\circ} \mathrm{C}$. Na comparação com outras estratégias de desenho urbano, como uso de vegetação e alterações na geometria do cânion, o albedo teve participação menor como alternativa tanto para redução da temperatura do ar como para redução do estresse térmico.

Portanto, embora o potencial do efeito de aumento do albedo na redução das temperaturas de superfície seja indiscutível, há um debate sobre a viabilidade e eficácia do uso do albedo como estratégia passiva para redução tanto do estresse térmico no nível do pedestre como do consumo de energia em climatização em edifícios. Há ainda a influência do clima local e da morfologia urbana sobre o impacto efetivo de alterações no albedo, os quais regulam os ganhos de calor e os fenômenos de trocas térmicas e radiantes com a atmosfera e objetos do entorno. A importância de se obter uma melhor compreensão dos efeitos de alterações no albedo sobre o microclima urbano está em permitir uma avaliação mais abrangente das possíveis vantagens e desvantagens dessa estratégia no ambiente urbano. Soma-se a isso a necessidade de se identificar os fatores urbanísticos (orientação de fachada e de eixo da caixa de rua, razão de aspecto do cânion urbano ou relação $\mathrm{H} / \mathrm{W}$ ) que mais fortemente influenciam seu uso efetivo e quais regiões e condições são mais propícias ou não para seu uso.

Tal conhecimento é importante ainda para guiar diretrizes de urbanização e legislações edilícias em uma direção de menor impacto energético e ambiental, e de melhoria da qualidade e conforto térmico dos espaços públicos urbanos. Deve-se frisar que a elevação da temperatura no plano do pedestre é, em geral, desvantajosa em climas quentes, podendo ser eventualmente vantajosa em climas frios.

\section{Objetivo}

O objetivo deste artigo é avaliar a influência do efeito de alterações no albedo de superfícies urbanas sobre a temperatura do ar no interior de cânions urbanos e seus impactos sobre o grau de conforto térmico predito no nível do pedestre.

\section{Metodologia}

Utilizou-se como modelo numérico o programa computacional CAT v. 1.3 (ERELL; WILLIAMSON, 2006), um programa desenvolvido em Fortran que permite simulações de condições microclimáticas no interior de um cânion urbano infinito. Foi adicionalmente acoplado ao CAT o modelo de conforto térmico ITS, desenvolvido por Givoni (1963) e adaptado para cânions urbanos por Pearlmutter, Berliner e Shaviv (2007), e os resultados do CAT serviram como dados de entrada para a geração de resultados baseados no ITS. Dessa forma, valores de ITS forneceram uma predição de níveis de conforto térmico de pedestres nos cânions simulados.

As bases de dados adotadas foram imagens do satélite Landsat 8 (LAND..., 2013), dos anos de 2013 e 2014, disponibilizadas pela plataforma USGS Earth Explorer, obtidas por meio de acesso on line; e o ano climático típico (TMY) de cada localidade estudada foi obtido da base de dados da Antac (RORIZ..., 2012). Ressalta-se que a base de dados climáticos adotada foi gerada a partir de séries históricas relativamente curtas (10 anos de dados contínuos) das estações automáticas do INMET, por meio do método TMY, o que gerou uma dificuldade inicial de não se terem disponíveis dados de nebulosidade. Utilizou-se, em razão disso, um procedimento para deduzir os períodos de céu claro ou mais próximos dessa condição, conforme exposto na sequência. 


\section{Cenário e variáveis de simulação}

Para garantir a diversidade de cenários, foi selecionada uma cidade de cada uma das oito zonas bioclimáticas (ZBs) definidas na Norma Brasileira de Desempenho Térmico NBR 15220-1 a NBR 15220-3 (ABNT, 2005a, 2005b, 2005c).

Nesta pesquisa, as simulações foram realizadas considerando uma situação mais local, e, portanto, não se simula a influência do aglomerado urbano como um todo. Além disso, o tamanho da área urbana e a densidade populacional das cidades pertencente às diferentes ZBs são muito variáveis, sendo praticamente impossível obter-se uniformidade nas cidades amostrais. Dessa forma, para fins comparativos, optou-se por buscar, para cada $\mathrm{ZB}$, cidades de porte médio, com tamanho populacional o mais semelhante possível, com disponibilidade de dados climáticos, e que tivessem a localização da estação meteorológica de referência (ER) visível nas imagens de satélite.

Esse último critério fez parte da seleção das cidades amostrais, pois a posição exata da ER é importante para a caracterização do entorno, o qual influencia o balanço de energia superficial (BES) relativo à ER. A verificação nas imagens de satélite foi relevante, pois é muito comum que as coordenadas fornecidas oficialmente estejam incorretas ou que haja imprecisão nos relatórios de dados. A localização geográfica das cidades amostrais é apresentada na Tabela 1.

Para as cidades amostrais, foram definidos locais para o posicionamento de um cânion urbano para estudo. No modelo de simulação aqui adotado, as condições de entorno interferem na porcentagem de fontes de umidade ao redor do cânion. O objetivo nesse caso não foi o de uniformizar as condições, mas apenas o de obter dados de entrada para o entorno que estivessem relacionados às condições reais de cada cidade, em uma zona de potencial adensamento urbano.

\section{Simulações das condições microclimáticas no cânion}

O espaço urbano não é constituído de uma superfície horizontal plana e sem obstruções, mas está inserido na geometria urbana. O efeito do albedo é impactado por essa geometria, pela influência conjunta das alterações de exposição solar e pelas condições microclimáticas. Para simular o efeito do albedo no interior de um cânion urbano, foi utilizado o programa computacional CAT (ERELL; WILLIAMSON, 2006), descrito anteriormente. O CAT é capaz de predizer a temperatura do ar e umidade relativa em um cânion urbano com base em dados climáticos obtidos em estações meteorológicas convencionais e em características geométricas e físicas de ambas as localidades (cânion e estação meteorológica).

Assumindo-se que o cânion simulado e a estação meteorológica de referência estão sujeitos às mesmas condições mesoclimáticas, diferenças em seus microclimas devem-se à influência de características de superfície de cada local sobre os processos de troca de energia. Assim, a partir da caracterização da geometria e do entorno dos dois locais (cânion e estação meteorológica), é calculado o balanço de energia para a estação meteorológica, para as superfícies do cânion e para o seu volume de ar. Com base nas variáveis medidas na estação de referência e nas diferenças no balanço de energia entre os dois locais obtém-se a predição das variáveis microclimáticas no interior do cânion.

Para manter a simplicidade do modelo, assume-se que há uma distribuição homogênea da temperatura no cânion, bem como de cada superfície do cânion, individualmente. As diferenças entre as fontes de umidade no entorno do cânion e da estação meteorológica permitem o ajuste do particionamento entre calor latente e sensível no balanço de energia do cânion simulado.

Tabela 1 - Cidades amostrais representantes de cada zona bioclimática

\begin{tabular}{c|c|c|l|c|c|c}
\hline ZB & Pop. (milhões) & UF & \multicolumn{1}{|c|}{ Cidade } & Lat. & Long. & $\begin{array}{c}\text { Classificação } \\
\text { Köppen-Geiger }\end{array}$ \\
\hline 1 & 0,357 & PR & Maringá & $-23,41$ & $-51,93$ & Cfb \\
2 & 0,125 & RS & Uruguaiana & $-29,84$ & $-57,08$ & Cfa \\
3 & 0,516 & MG & Juiz de Fora & $-21,77$ & $-43,36$ & Cfa \\
4 & 0,318 & SP & Franca & $-20,58$ & $-47,38$ & Cfb \\
5 & 0,463 & RJ & Campos dos Goytacazes & $-21,72$ & $-41,34$ & Aw \\
6 & 0,207 & SP & Presidente Prudente & $-22,12$ & $-51,40$ & Cfa \\
7 & 0,247 & MA & Imperatriz & $-5,56$ & $-47,46$ & Aw \\
8 & 0,327 & ES & Vitória & $-20,32$ & $-40,32$ & Aw \\
\hline
\end{tabular}

Fonte: População: IBGE (2012), Classificação Köppen-Geiger: Kottek et al. (2006) e Coordenadas da ER: Localização das estações meteorológicas dos arquivos climáticos das localidades analisadas, conforme aparecem nos arquivos climáticos, ajustada a partir da identificação da estação na imagem do Google Earth (GOOGLE, 2014a).

92 Krüger, E. L.; Gonzalez, D. E. G. 
Em outras palavras, o CAT transpõe as variáveis microclimáticas medidas na estação meteorológica de referência para o interior de um cânion urbano, ajustando-as de acordo com as condições de balanço de energia impostas pela geometria do cânion e predizendo a temperatura do ar no seu interior com maior acurácia do que a adoção direta dos valores medidos na estação meteorológica.

Para o balanço energético de superfície, a distribuição dos fluxos energéticos se dá segundo a Equação 1:

$\mathrm{Q}^{*}+\mathrm{QF}=\mathrm{QH}+\mathrm{QE}+\Delta \mathrm{QS}+\Delta \mathrm{QA}$

Onde:

Q*: é o saldo líquido de fluxo de energia radiante em todos os comprimentos de onda;

QF: é o fluxo de calor antropogênico;

$\mathrm{QH}$ : é o fluxo vertical de calor sensível devido à convecção ou turbulência;

QE: é o fluxo de calor latente;

$\Delta \mathrm{QS}$ : é o saldo líquido de fluxo de calor armazenado no solo; e

$\Delta$ QA: é o saldo líquido de fluxo horizontal de calor sensível devido à advecção.

Todos os termos da Equação 1 são calculados em CAT com base em dados disponíveis na estação meteorológica e nas características do cânion. A temperatura no cânion é computada somando-se a temperatura do ar encontrada na estação meteorológica com o saldo líquido em termos de temperatura resultante das características de ambos os sítios, segundo procedimento detalhado em Erell e Williamson (2006).
A validação do modelo CAT quanto à predição da temperatura do ar no interior de um cânion foi realizada com base em medições de campo em dois cânions de razão de aspecto (H/W) de 1,35, localizados no centro da região metropolitana de Adelaide, Austrália, entre 2000 e 2001, com a utilização de dados de referência de uma estação meteorológica distante $1,7 \mathrm{~km}$ desses cânions (ERELL; WILLIAMSON, 2006). Posteriormente, o CAT foi revisado para incorporar um método de consideração da influência da umidade do entorno na umidade disponível no cânion simulado por meio da advecção, tendo sido testado por Erell et al. (2010) com dados meteorológicos medidos em um cânion de H/W de 2,1 em Göteborg, Suécia.

A calibração pode ser realizada alterando-se os coeficientes do modelo de histerese de armazenamento de energia (CAMUFFO; BERNARDI, 1982), que aproxima o padrão de variação no armazenamento de energia de acordo com a variação do saldo líquido de radiação ao longo do ano, e utilizado para determinação de $\Delta \mathrm{QS}$; os dados relacionados à umidade do solo; e os coeficientes que determinam a natureza do fluxo de ar que atravessa o cânion.

Dessa forma, no CAT, além dos dados de identificação de cada registro de entrada (ano, mês, dia e hora), são necessários dados relativos à estação meteorológica de referência (ER) e do local do cânion simulado (CS), os quais são inseridos individualmente ou sob a forma de lista com dados horários. Tais dados estão apresentados de forma resumida nos Quadros 1 e 2, respectivamente.

Quadro 1 - Dados de entrada relativos à estação meteorológica de referência

\begin{tabular}{|l|l|}
\hline DADO & \multicolumn{1}{c|}{ DESCRIÇÃO } \\
\hline $\mathrm{T}_{\mathrm{ER}}$ & Temperatura de bulbo seco (TBS) na ER, em ${ }^{\circ} \mathrm{C}$ \\
\hline $\mathrm{UR}_{\mathrm{ER}}$ & Umidade relativa do ar (UR) na ER, em \% \\
\hline $\mathrm{u}_{\mathrm{ER}}$ & Velocidade do vento a $10 \mathrm{~m}$ de altura na ER, em $\mathrm{m} / \mathrm{s}$ \\
\hline udir $_{\mathrm{ER}}$ & $\begin{array}{l}\text { Direção do vento, em graus decimais (Norte }=0^{\circ}, \mathrm{com} \text { angulação } \\
\text { azimutal crescente no sentido horário) }\end{array}$ \\
\hline $\mathrm{N}$ & Cobertura de nuvens, em décimos de céu \\
\hline $\mathrm{P}$ & Chuva total acumulada na última hora, em $\mathrm{mm}$ \\
\hline $\mathrm{K}_{\mathrm{G}}$ & Radiação solar global no plano horizontal, em $\mathrm{W} / \mathrm{m}^{2}$ \\
\hline $\mathrm{K}_{\mathrm{D}}$ & Radiação difusa no plano horizontal, em $\mathrm{W} / \mathrm{m}^{2}$ \\
\hline $\mathrm{h}_{\mathrm{S}}$ & Altura solar, em graus decimais (acima do horizonte) \\
\hline $\mathrm{Az}$ & $\begin{array}{l}\text { Azimute solar, em graus decimais (Norte }=0^{\circ}, \text { com angulação } \\
\text { azimutal crescente no sentido horário) }\end{array}$ \\
\hline $\mathrm{IV}_{\text {céu }}$ & $\begin{array}{l}\text { Radiação infravermelha (onda longa) vinda da abóbada celeste, em } \\
\text { W/m }\end{array}$ \\
\hline
\end{tabular}


Os dados relativos à ER foram obtidos com base nos respectivos anos climáticos de referência, com exceção da altura solar (hs) e do azimute solar (Azs), que foram calculados com base nas planilhas de cálculo de posição solar disponibilizadas pela agência norte-americana National Oceanic and Atmospheric Administration (NATIONAL..., 2014), e adaptados a cada situação analisada. Foram utilizados os valores de elevação solar que consideram a refração atmosférica aproximada.

Os dados de geometria do cânion foram fixados para fins de simulação (ver seção Metodologia), variando-se apenas a orientação do eixo do cânion estudado. Os valores-padrão (default do programa CAT) relativos às condições de mistura do ar atmosférico, ao armazenamento de calor e o modelo LUMPS- $\beta$ (GRIMMOND; OKE, 2002) foram mantidos.

De ambos os locais (ER e CS), o modelo CAT exige uma descrição das características do terreno de entorno, por meio da existência de fontes geradoras de umidade no entorno.

Estabeleceu-se um procedimento padronizado para a identificação e quantificação da disponibilidade de umidade no entorno de cada cidade e situação analisadas. Como esta pesquisa aplica o CAT a diferentes cidades, foi necessário que se estabelecesse um procedimento com maior padronização e uniformidade para a identificação e quantificação das fontes de umidade. Optou-se pelo cálculo com base no tratamento e na classificação de imagens de satélite, com o uso combinado de três bandas do satélite Landsat 8 (regiões espectrais: azul visível, infravermelho próximo e infravermelho curto). Desse modo, a estimativa da disponibilidade de umidade ao redor de cada área deixou de ser feita visualmente, introduzindo-se maior precisão nos dados de análise. A caracterização das fontes de umidade do entorno envolveu a discriminação das porcentagens de vegetação e corpos d'água em 33 setores, que cobrem a área de entorno no raio de 1 km (Figura 1).

Para a estação meteorológica, é necessário fornecer também parâmetros que estabeleçam o efeito da rugosidade do terreno sobre o perfil vertical de vento ( $\mathrm{Zd}$ e $\mathrm{Z} 0$ ), que foram estimados com base no índice de densidade de área plana (Figura 2-b-c) e da sua correlação com os parâmetros de rugosidade normalizados $\left(Z_{0} / \overline{Z_{H}}\right.$ e $Z_{d} / \overline{Z_{H}}$ ) (Figura 2 -a). A altura média $\left(\overline{Z_{H}}\right)$ das edificações foi estimada visualmente por meio de comprimentos de sombras e da ferramenta Google Street View (GOOGLE, 2014b).

\section{Quadro 2 - Dados de descrição do local do cânion simulado e da estação meteorológica}

\begin{tabular}{|c|c|}
\hline DADO & DESCRIÇÃ̃O \\
\hline$\alpha \mathrm{P}, \alpha \mathrm{F}$ & Albedo médio do piso do cânion e albedo médio das fachadas do cânion, adimensionais. \\
\hline$L, \mathrm{H} 1, \mathrm{H} 2$ & Descrição geométrica do cânion, em metros (largura do cânion e alturas de cada fachada). \\
\hline $\begin{array}{l}\text { H1v, D1v, } \\
\text { H2v, D2v }\end{array}$ & $\begin{array}{l}\text { Descrição geométrica dos edifícios vizinhos ao cânion, em metros (altura das fachadas } \\
\text { vizinhas e distância das fachadas vizinhas à linha de fachadas do cânion). }\end{array}$ \\
\hline Azc & Orientação geográfica do eixo do cânion, em graus decimais (azimute). \\
\hline $\begin{array}{l}\text { AP1-3, } \\
\text { AF } 1-3\end{array}$ & $\begin{array}{l}\text { Coeficientes que descrevem o padrão de armazenamento de calor do piso e das fachadas } \\
\text { (modelo de histerese de armazenamento de energia de Camuffo e Bernardi (1982)), } \\
\text { coeficientes adimensionais determinados empiricamente. }\end{array}$ \\
\hline Mix 1-5 & $\begin{array}{l}\text { Razões de mistura do ar atmosférico para cada uma das cinco condições de estabilidade } \\
\text { atmosférica consideradas pelo CAT (inversão atmosférica, atmosfera estável, atmosfera } \\
\text { neutra, condição turbulenta, atmosfera superestável), adimensionais, que afetam o cálculo } \\
\text { de trocas de energia por turbulência do ar, determinadas empiricamente. }\end{array}$ \\
\hline LUMPS- $\beta$ & $\begin{array}{l}\text { Coeficiente beta do modelo LUMPS, do inglês local-scale urban meteorological } \\
\text { parametrization scheme, estabelecido por Grimmond e Oke (2002), que ajusta a } \\
\text { defasagem de tempo na inversão do sentido de fluxo de calor sensível entre o solo e a } \\
\text { atmosfera após o pôr do sol. }\end{array}$ \\
\hline $\begin{array}{l}\text { Pva, } \\
\text { Pv1-32, } \\
\text { Pa1-32 }\end{array}$ & $\begin{array}{l}\text { Fontes de umidade na área de entorno, respectivamente: percentual de vegetação e corpos } \\
\text { d'água do setor central, percentual de vegetação em cada setor dos anéis interno e externo, } \\
\text { percentual de corpos d'água em cada setor dos anéis interno e externo. }\end{array}$ \\
\hline $\mathrm{Zd}, \mathrm{Z0}$ & $\begin{array}{l}\text { Dados relativos ao efeito da rugosidade do terreno sobre o perfil vertical de velocidade do } \\
\text { vento: deslocamento do plano zero e comprimento de rugosidade, respectivamente, em } \\
\text { metros, aplicados na descrição do local da estação meteorológica de referência apenas, } \\
\text { que podem ser estimados a partir de sua correlação com a densidade de área plana, } \\
\text { estabelecida por Grimmond e Oke (1999). }\end{array}$ \\
\hline
\end{tabular}

94 Krüger, E. L.; Gonzalez, D. E. G. 
Figura 1 - Setores para discriminação das fontes de umidade no raio de $1 \mathrm{~km}$ no entorno, ilustradas sobre: (a) imagem de satélite e (b) imagem já classificada segundo o tipo de cobertura do solo

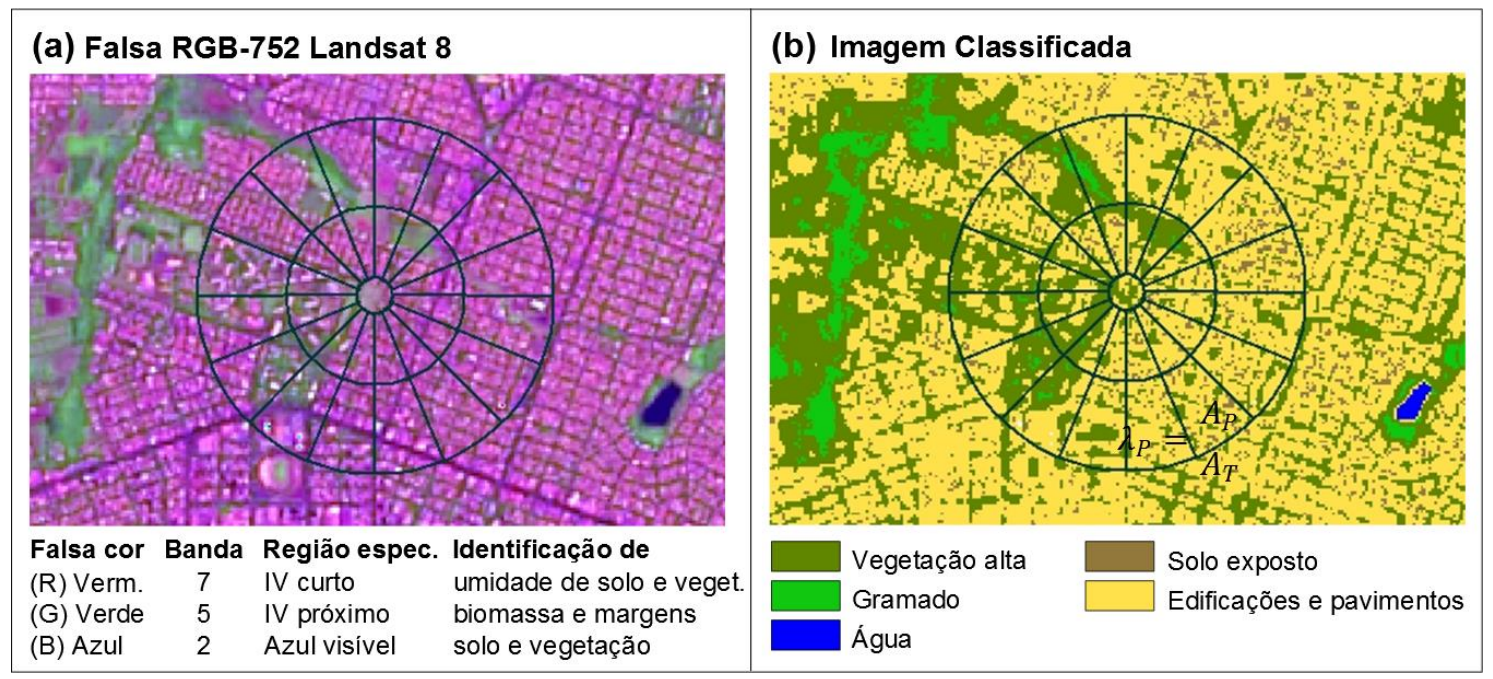

Figura 2 - (a) Correlação aproximada entre a densidade de área plana e os parâmetros de rugosidade do terreno, (b) ilustração e definição do índice de densidade de área plana e (c) entorno da estação meteorológica de Maringá-PR com áreas edificadas marcadas

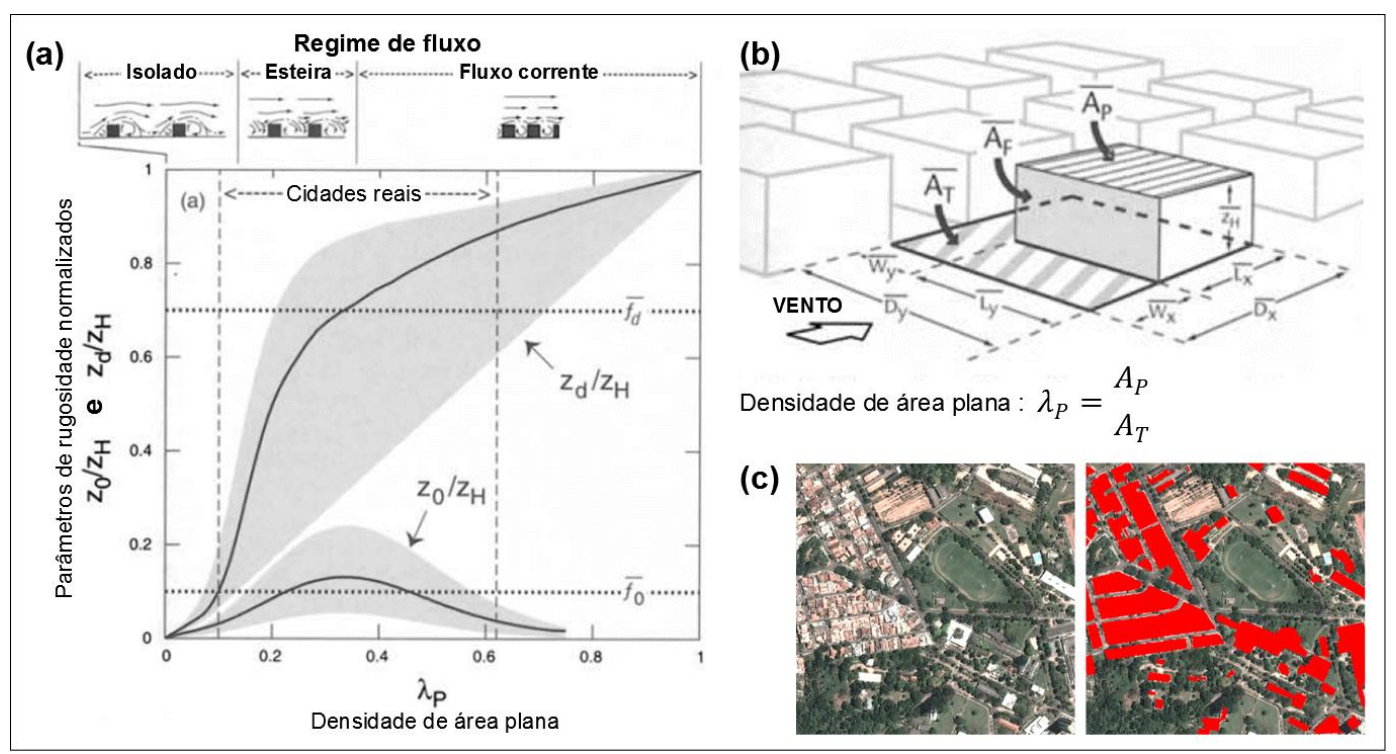

Fonte: (a e b) adaptados de Grimmond e Oke (1999) e (c) adaptado de Google Earth (GOOGLE, 2014a).

\section{Relatório de saída do CAT}

O CAT fornece como dados de saída valores relativos aos cálculos da própria simulação e ao balanço de energia, incluindo aqueles relacionados às variáveis microclimáticas (Quadro 3), relevantes para a análise térmica e de conforto (índice ITS) do efeito do albedo.

\section{Forma e orientação do cânion adotadas nas simulações}

A geometria escolhida para os cânions de estudo representa edifícios com a altura máxima permitida sem o uso de elevador (pavimento térreo acrescido de mais quatro pavimentos), com $15 \mathrm{~m}$ de altura, separados por via local, também com $15 \mathrm{~m}$ de largura, resultando em um cânion de razão altura/largura $(\mathrm{H} / \mathrm{W})$ de 1. Essa configuração foi adotada por ser um quadro plausível de adensamento de bairros residenciais de média 
renda em cidades de porte médio brasileiras. Optou-se por não se considerar cânions assimétricos para as análises. Uma vez que o efeito do albedo de superfície é dependente da exposição solar e que, no interior do cânion, a exposição é influenciada pela orientação solar, para captar a influência indireta da orientação do cânion sobre o efeito do albedo, duas orientações foram simuladas: cânion com eixo alinhado no sentido $\mathrm{N}$ $\mathrm{S}\left(\mathrm{AzC} 1=0^{\circ}\right)$ e no sentido L-O $\left(\mathrm{AzC} 2=90^{\circ}\right)$.

\section{Escolha dos dias de céu claro}

Uma vez que tanto o efeito do albedo como a intensidade da ICU são máximos sob condições de céu claro, foram selecionados um dia de céu claro de inverno e outro de verão (dias amostrais) para serem utilizados na comparação entre os cenários, embora o ano todo seja simulado e analisado.

A base de dados climáticos usada para as simulações não contém dados de nebulosidade, e, devido à sua falta, foi necessária a observação da curva diária de radiação solar direta para assegurar condição de céu claro. Selecionaram-se, para os meses de interesse, cinco dias em que a máxima diária de radiação global tivesse os valores mais próximos de $95 \%$ da máxima mensal. Isso garantiu a escolha de dias com os maiores picos de radiação. Entre os cinco dias pré-selecionados, os gráficos da curva diária de radiação global foram observados visualmente, sendo escolhido o dia cuja forma da curva de radiação melhor correspondesse à resposta típica de céu claro, ou seja, uma curva suave e contínua em forma senoidal, com pico na hora central do dia.
As ZBs 2 e 7 seguiram regra diferenciada devido aos seus altos níveis de nebulosidade. Foi escolhido o dia de menor porcentagem de radiação difusa relativamente à global. Para um céu absolutamente limpo e claro, em altura solar próxima ao zênite, a taxa entre a radiação difusa e a global cai para algo entre $10 \%$ e $15 \%$, o que aumenta seu valor conforme aumenta a turbidez atmosférica (MONTEITH; UNSWORTH, 2013). Nas cidades analisadas, em dia de céu claro, a taxa entre a radiação difusa e global parte de um valor mínimo de $20 \%$ da radiação solar global nos dias amostrais, tendo uma participação mais alta nas ZBs 1, 2 e 6 (Figura 3). Nem sempre foi possível obter as condições perfeitas de céu claro, mas os cuidados na escolha do dia objetivaram garantir que o dia amostral fosse o mais próximo possível do ideal para as simulações.

\section{Variações de albedo testadas}

O efeito do albedo no interior do cânion urbano foi analisado comparando-se diretamente situações extremas de albedo para cada superfície, uma com valores de albedo alto (AA) e outra com valores de albedo baixo (AB). Valores de albedo diferem, porém, em função do tipo de superfície. Fachadas possibilitam o emprego de uma gama mais extensa de valores de albedo, comumente com grande variedade de materiais e cores; enquanto o piso permite basicamente o uso de asfalto e concreto como os materiais mais comuns adotados na pavimentação urbana, limitando a extensão da gama de valores de albedo atribuídos. Os valores adotados são descritos na Tabela 2 .

Quadro 3 - Dados de saída simulados pelo CAT utilizados na pesquisa

\begin{tabular}{|l|l|c|c|}
\hline \multicolumn{1}{|c|}{ DADO } & \multicolumn{1}{|c|}{ DESCRIÇÃ } & $\begin{array}{c}\text { Dados para } \\
\text { análise } \\
\text { térmica }\end{array}$ & $\begin{array}{c}\text { Dados para } \\
\text { o cálculo do } \\
\text { ITS }\end{array}$ \\
\hline TCS & $\begin{array}{l}\text { Temperatura de bulbo seco do ar prevista para o } \\
\text { interior do cânion, em }{ }^{\circ} \mathrm{C}\end{array}$ & $\times$ & $\times$ \\
\hline URCS & $\begin{array}{l}\text { Umidade relativa do ar prevista para o interior do } \\
\text { cânion, em \% }\end{array}$ & & $\times$ \\
\hline TP & $\begin{array}{l}\text { Temperatura estimada da superfície do piso (temp. } \\
\text { sol-ar), em }{ }^{\circ} \mathrm{C}\end{array}$ & $\times$ & $\times$ \\
\hline TD & $\begin{array}{l}\text { Temperatura estimada da superfície da fachada } 1, \text { à } \\
\text { direita da seção do cânion (temp. sol-ar), em }{ }^{\circ} \mathrm{C}\end{array}$ & $\times$ & $\times$ \\
\hline TE & $\begin{array}{l}\text { Temperatura estimada da superfície da fachada } 2, \text { à } \\
\text { esquerda da seção do cânion (temp. sol-ar), em }{ }^{\circ} \mathrm{C}\end{array}$ & $\times$ & $\times$ \\
\hline uCS & $\begin{array}{l}\text { Velocidade do vento à altura do pedestre, no interior } \\
\text { do cânion, em m/s }\end{array}$ & & $\times$ \\
\hline
\end{tabular}


Figura 3 - Distribuição da radiação solar direta e difusa (anos climáticos) para os dias de inverno e verão selecionados, em condições de céu claro

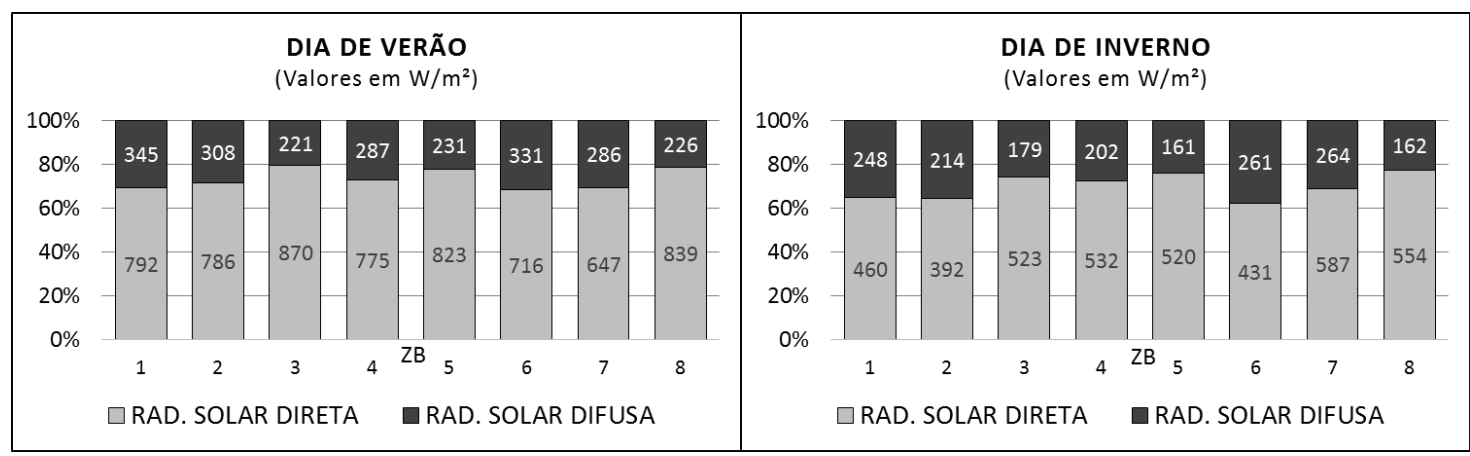

Tabela 2 - Valores de albedo usados nas simulações

\begin{tabular}{l|l|l|c}
\hline Superfície & \multicolumn{1}{|c|}{ Albedo } & \multicolumn{1}{c}{ Material } & Valor adotado \\
\hline \multirow{2}{*}{ Paredes } & Alto (AA) & Pintura clara e limpa & 0,70 \\
\cline { 2 - 4 } & Baixo (AB) & Pintura escura & 0,20 \\
\hline \multirow{2}{*}{ Piso } & Alto (AA) & Concreto claro & 0,45 \\
\cline { 2 - 4 } & Baixo (AB) & Asfalto & 0,15 \\
\hline
\end{tabular}

\section{Índice de conforto térmico adotado nas análises}

Para a avaliação do conforto térmico ao plano do pedestre foi utilizado o ITS, cujos cálculos foram realizados com o uso de planilhas eletrônicas para todas as horas do ano e para cada cenário simulado. De acordo com Pearlmutter, Berliner e Shaviv (2007), o ITS é um modelo biofísico, que representa a taxa de calor a ser transferida para o meio pela transpiração para que seja mantido o equilíbrio térmico do corpo com o meio, e é obtido mediante as Equações 2 e 3.

ITS = E.f-1

Eq. 2

Onde:

$\mathrm{E}=$ taxa de resfriamento por transpiração

requerida para a manutenção do equilíbrio térmico, em W/m²; e

$\mathrm{F}=$ coeficiente de eficiência da transpiração.

$\mathrm{E}=(\mathrm{M}-\mathrm{W}) \pm \mathrm{R}^{*} \pm \mathrm{C}$

Onde:

$\mathrm{M}=$ taxa metabólica, em $\mathrm{W} / \mathrm{m}^{2}$;

$\mathrm{W}=$ energia metabólica transformada em trabalho, em $\mathrm{W} / \mathrm{m}^{2}$;

$\mathrm{R}^{*}$ = radiação líquida, sobre cilindro de área equivalente ao do corpo, em W/m²; e

$\mathrm{C}=$ troca de calor sensível por convecção, em $\mathrm{W} / \mathrm{m}^{2}$.

A importância do ITS é que tal índice reflete mais fortemente a relação do corpo com o meio circundante em termos de trocas de energia, calculando a resposta fisiológica requerida para o corpo se manter em equilíbrio, em Watts (PEARLMUTTER, 2015). Segundo Pearlmutter (2015), embora se tenha uma noção intuitiva do efeito de mudanças na temperatura, o corpo possui receptores não para essa variável, mas para fluxos térmicos. Tal fato sugere haver uma relação mais direta entre índices como o ITS, cujos resultados são expressos em termos de fluxo de calor, e a sensação térmica humana, do que índices expressos em temperatura equivalente, como o PET, por exemplo. No caso do presente estudo, a utilização do ITS permitiu avaliar as parcelas integrantes do fluxo térmico recebido por um pedestre hipotético no centro do cânion urbano, de forma independente.

Para o cálculo do ITS, os dados de saída do CAT (Quadro 3) foram utilizados para alimentar os dados de entrada do modelo de conforto térmico. O Quadro 4 descreve os dados necessários ao cálculo do ITS nas simulações. A velocidade do ar no nível do pedestre e a temperatura do ar são utilizadas no cálculo das trocas térmicas por convecção, e a temperatura sol-ar (TSA) junto às superfícies do cânion é utilizada como aproximação da temperatura superficial, para que se calcule a radiação de onda longa (OL) emitida pelas superfícies.

A radiação líquida $\left(\mathrm{R}^{*}\right)$ é obtida por meio dos saldos de radiação de onda curta e onda longa (OC e OL, respectivamente), calculados para as condições geométricas e de exposição solar do interior do cânion. 
Quadro 4 - Dados necessários ao cálculo dos níveis de conforto térmico pelo ITS

\begin{tabular}{|l|l|l|}
\hline DADO & \multicolumn{1}{|c|}{ DESCRIÇÃO } & \multicolumn{1}{|c|}{ FONTE DOS DADOS } \\
\hline$B$ & $\begin{array}{l}\text { Altura do cilindro que representa o corpo do } \\
\text { pedestre }\end{array}$ & $\begin{array}{l}\text { Lit. Pearlmutter, Berliner e Shaviv } \\
(2007)\end{array}$ \\
\hline$\varnothing$ & $\begin{array}{l}\text { Diâmetro do cilindro que representa o corpo do } \\
\text { pedestre }\end{array}$ & $\begin{array}{l}\text { Lit. Pearlmutter, Berliner e Shaviv } \\
(2007)\end{array}$ \\
\hline$M-W$ & Parte da taxa metabólica transformada em calor & Lit. Erell et al. (2014) \\
\hline$R^{*}$ & $\begin{array}{l}\text { Radiação líquida, sobre cilindro de área } \\
\text { equivalente ao do corpo, em W/m }{ }^{2}\end{array}$ & TMY, PS, CAT \\
\hline$C$ & Troca de calor sensível por convecção & CAT \\
\hline$a_{B}$ & Absortância do pedestre & Lit. Erell et al. (2014) \\
\hline$\alpha_{h}, \alpha_{v}$ & Albedo das superfícies horizontais e verticais & $\begin{array}{l}\text { Lit. Brown e Dekay (2004), Gartland } \\
\text { (2010) e Oke (2002) }\end{array}$ \\
\hline$\varepsilon$ & Emissividade das superfícies e do pedestre & $\begin{array}{l}\text { Lit. American Society for Testing and } \\
\text { Materials (1986) }\end{array}$ \\
\hline $\mathrm{T}_{\mathrm{B}}$ & Temperatura média corporal & $\begin{array}{l}\text { Lit. Pearlmutter, Berliner e Shaviv } \\
(2007)\end{array}$ \\
\hline $\mathrm{f}$ & Coeficiente de eficiência da transpiração & AMT, PS, CAT \\
\hline$C l$ & Coeficiente de vestimenta: vestimenta leve & $\begin{array}{l}\text { Lit. Erell, Pearlmutter e Williamson } \\
\text { (2011) }\end{array}$ \\
\hline
\end{tabular}

Fonte: TMY: Ano Meteorológico Típico (RORIZ..., 2012); PS: Posição Solar: altitude e azimute solar (Planilha NOAA (NATIONAL..., 2014)); e CAT: Dados de saída do CAT.

Destaca-se que a radiação líquida $\left(\mathrm{R}^{*}\right)$ é composta pelos ganhos por radiação de OC e OL oriunda da abóbada, pelos ganhos por radiação de OC refletida pelas superfícies do cânion, e pelo saldo líquido entre a radiação de OL emitida pelas superfícies do cânion para o pedestre e aquela emitida pelo próprio pedestre para o meio.

Com base em dados coletados das diversas fontes descritas no Quadro 4, foi possível calcular, para cada hora referente aos dados climáticos do ano meteorológico típico, a temperatura do ar, a temperatura das superfícies do cânion, o valor de ITS e o nível de conforto relacionado a ele (segundo a Tabela 3) e os diversos componentes de fluxo de calor sobre o pedestre.

\section{Resultados e discussões \\ Potencial de redução da temperatura do ar}

Durante a maior parte do tempo, o aumento do albedo tem como efeito uma redução da temperatura do ar; no entanto, em horários pontuais também ocorre o efeito contrário, de forma que a adoção de médias com todos os dados poderia distorcer a análise. Por isso, os resultados que indicaram redução na temperatura do ar devido ao aumento do albedo, e que por simplicidade serão referidos como resultados de resfriamento, foram tratados separadamente daqueles que indicaram aumento na temperatura do ar, referidos como aquecimento.

Para a análise comparativa, adotou-se o valor do acumulado diário médio calculado sobre todos os valores horários simulados para o ano (Equações 4 e 5), para acentuar eventuais diferenças entre os cenários estudados. A Figura 4 mostra esses valores equivalentes diários (barras) e também a ordem de grandeza máxima do efeito horário e sua variação ao longo do ano, por meio do maior e do menor efeito horário máximo mensal (linhas).

$$
\begin{aligned}
& \overline{R f_{\text {dia }}}=\frac{\sum \Delta T_{a r}}{365} ; \text { para: } \Delta T_{a r}=\left(T_{a r, A A}-T_{a r, A B}\right)< \\
& 0 \quad \text { Eq.4 } \\
& \overline{A q_{d l a}}=\frac{\sum \Delta T_{a r}}{365} ; \text { para }: \Delta T_{a r}=\left(T_{a r, A A}-T_{a r, A B}\right)> \\
& 0
\end{aligned}
$$

$\overline{R f_{\text {dıa }}}=$ equivalente diário dos resultados de resfriamento acumulados no ano, em ${ }^{\circ} \mathrm{C}$;

$\overline{A q_{d ı a}}=$ equivalente diário dos resultados de aquecimento acumulados no ano, em ${ }^{\circ} \mathrm{C}$;

$\Delta T_{a r}=$ diferença horária na temperatura do ar resultante do aumento do albedo, em ${ }^{\circ} \mathrm{C}$;

$T_{a r, A A}=$ valor horário da temperatura do ar no cenário de albedo alto, em ${ }^{\circ} \mathrm{C}$; e

$T_{a r, A B}=$ valor horário da temperatura do ar no cenário de albedo baixo, em ${ }^{\circ} \mathrm{C}$. 
Tabela 3 - Níveis de conforto térmico relacionados ao valor de ITS

\begin{tabular}{l|c|c}
\hline VALOR DE ITS $(\mathbf{W})$ & NÍVEL ITS & NÍVEL DE CONFORTO TÉRMICO \\
\hline$\leq-160$ & 3 & Frio \\
\hline $\mathrm{de}-160 \mathrm{a}+160$ & 4 & Confortável \\
\hline $\mathrm{de}+160 \mathrm{a}+480$ & 5 & Morno \\
\hline $\mathrm{de}+480 \mathrm{a}+800$ & 6 & Quente \\
\hline$>+800$ & 7 & Muito quente \\
\hline
\end{tabular}

Fonte: Pearlmutter, Jiao e Garb (2014).

Embora as variações dos efeitos horários máximos em termos de redução ou aumento da temperatura do ar no cânion devido a modificações no albedo não sejam muito díspares em sua ordem de grandeza, os equivalentes diários não deixam dúvidas quanto à reduzida importância do efeito de aquecimento do ar local relativamente ao efeito benéfico de resfriamento do ar resultante da elevação do albedo. Os cânions N-S e L-O apresentam comportamentos bastante semelhantes, e a latitude também não parece influenciar diretamente o efeito do albedo sobre a temperatura do ar. Por sua natureza, é provável que esse parâmetro responda melhor às condições de vento, mistura atmosférica e advecção, as quais não foram avaliadas no presente trabalho.

Ainda que os valores máximos mensais de resfriamento horário sejam expressivos, variando algo em torno de $1{ }^{\circ} \mathrm{C}$ a $3{ }^{\circ} \mathrm{C}$, os demais valores horários simulados ficam em geral bastante aquém dos valores apresentados na Figura 4. Embora os efeitos de resfriamento possam ocorrer a qualquer hora do dia, ao se calcular os valores médios separados por mês e hora, nota-se para todos os cenários uma concentração muito forte do efeito médio de resfriamento durante as horas de sol do dia, com um pequeno deslocamento para mais tarde, e respondendo à variação sazonal de horas de sol.

Para ilustrar de forma resumida a ordem de grandeza do efeito horário médio do albedo em todas as cidades, a Tabela 4 reúne mês a mês, para o cânion N-S, o efeito horário ponderado de resfriamento por horas de sol de cada mês. A tabela mostra como os valores de redução da temperatura ambiente no período diurno são pouco significativos, variando de $0,11^{\circ} \mathrm{C}$ a $0,53{ }^{\circ} \mathrm{C}$ entre os diversos cenários estudados (os valores para o cânion L-O não são apresentados aqui, mas sua variação é de $0,11{ }^{\circ} \mathrm{C}$ a $0,39{ }^{\circ} \mathrm{C}$ ). Essa redução horária não é suficientemente significativa para, em si, melhorar o conforto térmico de pedestres.

\section{Efeito sobre o conforto térmico do pedestre}

Para ilustrar o efeito de alterações no albedo na sensação de conforto, foram isolados os componentes de ITS, representados em um gráfico como valores líquidos (saldos). Na Figura 5 são mostrados os resultados horários para um dia de céu claro amostral de verão e outro de inverno, do cânion N-S, para algumas cidades, selecionadas por semelhança da latitude local. As barras mostram a diferença causada pela mudança de albedo em cada componente do ITS, ou seja, o quanto um componente é acrescido ou diminuído com a substituição do $\mathrm{AB}$ por $\mathrm{AA}$. $\mathrm{O}$ efeito de alterações no albedo sobre trocas de calor por convecção (barras brancas) é tão pequeno que praticamente desaparece no gráfico. As barras amarelas mostram o acréscimo de radiação de OC refletida sobre o pedestre e as barras cinza mostram a redução de radiação de OL emitida para o pedestre. As barras em tonalidades mais claras mostram resultados para o dia de verão, e as barras mais escuras para o de inverno.

Para todas as latitudes, tanto no dia de verão como no de inverno, o aumento de radiação de OC refletida (barras amarelas) é maior do que a redução da radiação de OL emitida (barras cinza), o que resultou num saldo líquido positivo para albedo alto. $\mathrm{O}$ saldo líquido (linhas) representa o incremento de estresse térmico devido ao aumento do albedo: a linha vermelha mostra o saldo no dia de verão, enquanto a azul no de inverno. Como resultado, verifica-se que o cenário de AA implica em um ambiente de maior intensidade de radiação sobre o pedestre em comparação com o cenário de $\mathrm{AB}$, o que representa uma situação de maior estresse térmico, principalmente nas horas centrais do dia e em condições de calor. 
Figura 4 - Comparação do efeito do aumento do albedo sobre a temperatura do ar entre as cidades estudadas - faixa de variação das máximas mensais no ano, e valores diários equivalentes ao acumulado anual, em ${ }^{\circ} \mathrm{C}$

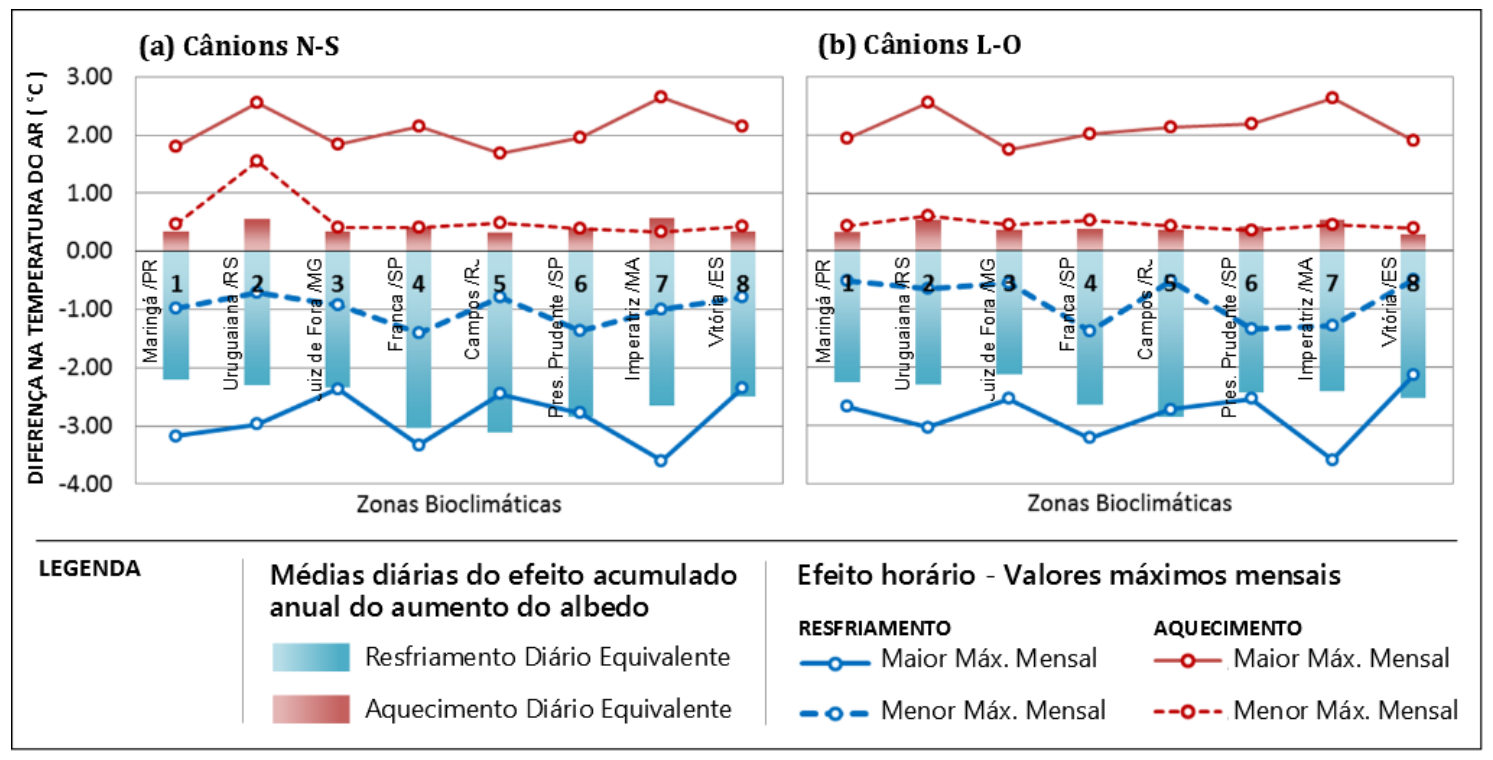

Tabela 4 - Efeito horário ponderado de resfriamento por horas de sol mês a mês $\left(\mathrm{em}^{\circ} \mathrm{C}\right)$

\begin{tabular}{c|c|c|c|c|c|c|c|c|c|c|c|c}
\hline ZB & jan. & fev. & mar. & abr. & maio & jun. & jul. & ago. & set. & out. & nov. & dez. \\
\hline 1 & $-0,14$ & $-0,16$ & $-0,26$ & $-0,21$ & $-0,21$ & $-0,17$ & $-0,19$ & $-0,16$ & $-0,17$ & $-0,16$ & $-0,19$ & $-0,16$ \\
\hline 2 & $-0,22$ & $-0,20$ & $-0,22$ & $-0,21$ & $-0,16$ & $-0,12$ & $-0,12$ & $-0,16$ & $-0,21$ & $-0,22$ & $-0,21$ & $-0,21$ \\
\hline 3 & $-0,13$ & $-0,15$ & $-0,19$ & $-0,25$ & $-0,30$ & $-0,17$ & $-0,34$ & $-0,28$ & $-0,21$ & $-0,14$ & $\mathbf{- 0 , 1 1}$ & $-0,12$ \\
\hline 4 & $-0,22$ & $-0,26$ & $-0,24$ & $-0,23$ & $-0,31$ & $-0,24$ & $-0,23$ & $-0,33$ & $-0,27$ & $-0,26$ & $-0,25$ & $-0,22$ \\
\hline 5 & $-0,21$ & $\mathbf{- 0 , 5 3}$ & $-0,35$ & $-0,29$ & $-0,25$ & $-0,20$ & $-0,21$ & $-0,23$ & $-0,27$ & $-0,17$ & $-0,21$ & $-0,16$ \\
\hline 6 & $-0,21$ & $-0,26$ & $-0,24$ & $-0,22$ & $-0,25$ & $-0,23$ & $-0,24$ & $-0,21$ & $-0,24$ & $-0,29$ & $-0,21$ & $-0,21$ \\
\hline 7 & $-0,23$ & $-0,22$ & $-0,23$ & $-0,21$ & $-0,20$ & $-0,26$ & $-0,23$ & $-0,23$ & $-0,25$ & $-0,20$ & $-0,18$ & $-0,17$ \\
\hline 8 & $-0,16$ & $-0,20$ & $-0,26$ & $-0,19$ & $-0,29$ & $-0,28$ & $-0,18$ & $-0,20$ & $-0,20$ & $-0,16$ & $-0,21$ & $-0,18$ \\
\hline
\end{tabular}

Figura 5 - Diferença no fluxo radiante entre os cenários $A A$ e $A B$

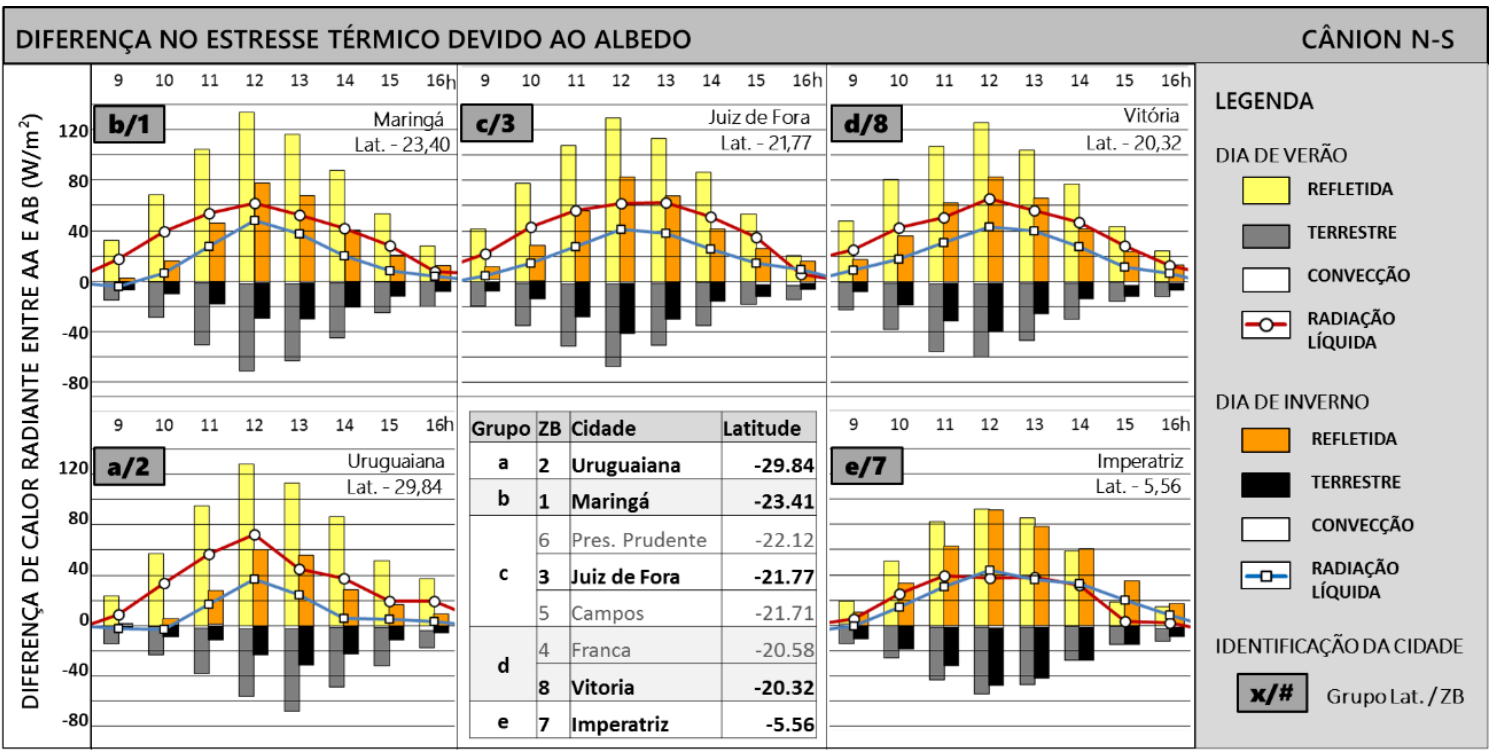


Em baixas latitudes os saldos de verão e de inverno são semelhantes, enquanto em altas latitudes há maior diferenciação entre eles, sendo o de inverno nitidamente menor. Isso indica que, nas latitudes mais altas, possível melhoria do conforto térmico do pedestre no inverno devido à alteração do albedo seria pouco efetiva, levando-se em conta os impactos prejudiciais ao conforto do aumento de estresse térmico no verão. Em baixas latitudes, o efeito sazonal é desprezível.

Esse resultado de piora do grau de conforto térmico devido a aumento dos valores de albedo das superfícies pode ser explicado pela defasagem de tempo entre o efeito da radiação refletida e a emitida. O efeito do albedo sobre a radiação refletida em direção ao pedestre é um efeito instantâneo no tempo. Já seu efeito sobre a temperatura das superfícies ocorre de forma gradual e cumulativa no tempo. Há ainda o fato de que parte do benefício de redução da temperatura da superfície é cancelada no interior do cânion, pois as superfícies adjacentes absorvem a radiação refletida pelas demais, aprisionando parte do calor, ao contrário das superfícies em campo aberto, nas quais a radiação é refletida em direção à atmosfera. Assim, uma maior quantidade de radiação OC é refletida para o pedestre, e nem toda a radiação refletida se converte em redução de temperatura superficial, havendo uma perda por reabsorção.

A Figura 6 mostra, para os dias de céu claro amostrais, o incremento de radiação sobre o pedestre devido ao aumento do albedo, em ambas as orientações de eixo do cânion, nas horas de pico. A magnitude do máximo incremento diário de calor radiante para os dias estudados varia em função da estação e orientação do cânion. No verão, o acréscimo é maior que no inverno, e essa diferença sazonal é mais intensa na cidade com latitude mais alta (Uruguaiana, RS, localizada na ZB 2), onde a maior diferença ocorre para ambas as orientações de cânion.

O fluxo de calor produzido pelo corpo devido ao seu metabolismo (taxa metabólica menos trabalho) considerado para o cálculo do ITS foi de $70 \mathrm{~W} / \mathrm{m}^{2}$. Note-se que no dia de verão amostral quase todas as cidades apresentam um incremento superior a $50 \mathrm{~W} / \mathrm{m}^{2}$ devido ao aumento do albedo na hora de pico, o que significa um acréscimo de $70 \%$ do calor produzido pelo próprio corpo, para ser dissipado pelo pedestre pela transpiração, e isso nas horas mais quentes do dia.

O incremento de estresse térmico é geralmente maior na condição de verão do que na de inverno, o que é consistente com maiores intensidades de radiação solar nesse período. Por outro lado, os resultados sugerem menores incrementos (e menor diferenciação sazonal) para baixas latitudes, onde a elevação solar é mais alta, atingindo os pedestres principalmente sobre a cabeça e os ombros, uma área de exposição corporal menor. Além disso, há nesse caso uma maior penetração dos raios solares no cânion, com redução nas reflexões internas.

O incremento máximo de radiação é bastante semelhante entre os cânions N-S e L-O para o dia de verão, quando em ambas as orientações a média entre as cidades é de $59 \mathrm{~W} / \mathrm{m}^{2}$ aproximadamente. $\mathrm{Na}$ condição de inverno, porém, há maior diferenciação entre as duas orientações de eixo, e a média entre cidades fica em torno de $42 \mathrm{~W} / \mathrm{m}^{2}$ para o cânion N-S e $25 \mathrm{~W} / \mathrm{m}^{2}$ para o L-O. Nessa orientação, os valores consideravelmente menores no dia de inverno, e em especial nas latitudes mais altas, devem-se em parte ao maior sombreamento no interior do cânion L-O quando a altura solar é mais baixa.

Em outras palavras, para essa proporção de cânion $(\mathrm{H} / \mathrm{W}=1)$, a orientação do cânion tem maior influência sobre o conforto do pedestre durante o inverno, devido às condições de sombreamento (ressalva-se que este estudo refere-se a um pedestre situado no centro do cânion). Isso evidencia que a geometria e orientação do cânion, ao regular os horários e períodos de exposição à radiação solar direta, pode ter uma influência tão ou mais significativa que o uso de albedos altos.

\section{Figura 6 - Máximo incremento de calor radiante para o pedestre devido a um aumento do albedo}
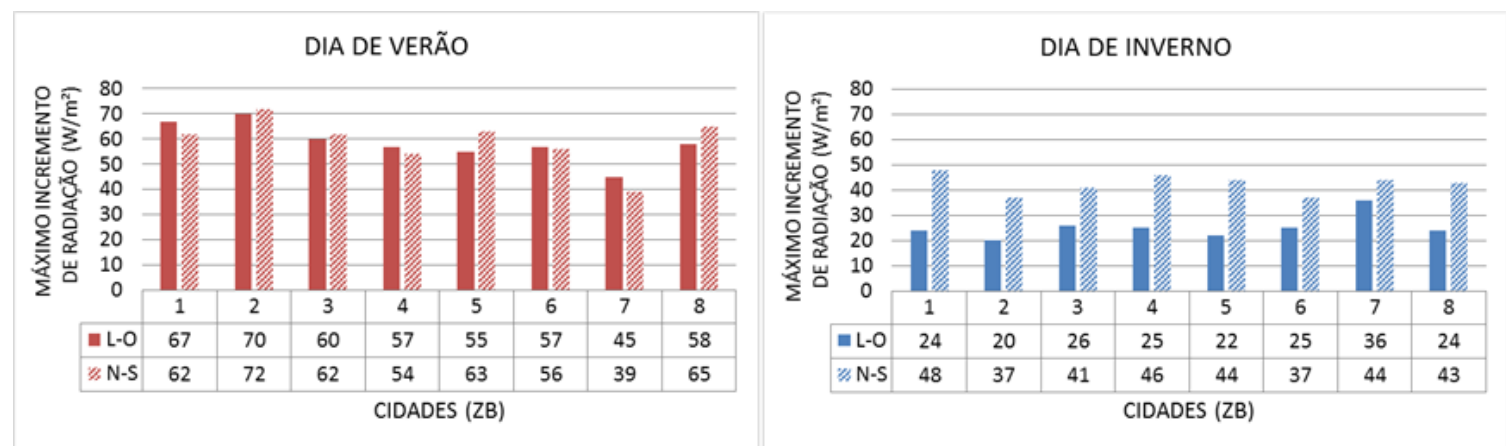
Na avaliação do efeito da orientação do cânion, a Figura 7 mostra o saldo líquido total de radiação (Rn) a ser perdido pelo pedestre pela transpiração, e as zonas de conforto relativas a cada nível de $\mathrm{Rn}$, tendo como exemplo o cenário de AA da cidade da ZB1 (Maringá, PR) por estar localizada no Trópico de Capricórnio.

Devido ao sombreamento matutino e vespertino, os cânions N-S mostram um perfil típico de maiores fluxos radiantes concentrados em torno do meio-dia, enquanto cânions L-O têm um perfil de valores altos distribuídos ao longo de todo o dia, representando uma condição de maior (e contínuo) estresse térmico para o pedestre. A intensidade desse efeito varia, é claro, de acordo com a latitude e estação do ano, mas é uma tendência geral.

Em latitudes mais altas, o cânion L-O representa uma condição de maior incremento de radiação durante o verão, quando este é menos desejável, e de menor incremento de radiação durante $o$ inverno, quando este pode ser interessante para aumento do conforto do pedestre.

Ao correlacionar os fluxos líquidos totais de estresse térmico com os níveis de conforto do ITS, para os dias de céu claro amostrais de todas as cidades, obtém-se a tabela de níveis de conforto hora a hora (Figura 8), na qual se vê mais claramente o efeito do aumento do albedo sobre as classes de conforto/desconforto térmico obtidas. Embora, na maioria dos casos, o total de horas de desconforto diárias seja o mesmo, nos dias de céu claro de verão, com AA, há um aumento visível de horas com nível 6 , classe ITS quente, que passam para o para nível 7 , muito quente.

Para o dia de céu claro de inverno, a variação do total de horas de desconforto e intensidade de desconforto não é tão pronunciada e o aumento de calor radiante devido ao albedo é muito ameno, corroborando a ideia de que o albedo provavelmente seja pouco eficiente na melhora do conforto de regiões frias, sendo, nesses casos, mais promissora a correta orientação do cânion.

Embora a componente de troca de calor por convecção entre o pedestre e o meio não seja um fator fortemente afetado por alterações de albedo no cânion (conforme Figura 5), tal componente é capaz de afetar o nível final de estresse térmico. Aqui se discute a orientação do cânion em relação aos ganhos por radiação, mas deve-se ressaltar que sua relação com a direção dos ventos em cada localidade também deve ser levada em conta, pois afeta as trocas de calor entre a camada de dossel e a atmosfera, influindo sobre o microclima, a concentração de poluentes e o conforto térmico de edifícios e pedestres.

\section{Conclusões}

Foi demonstrado que, para as situações analisadas, o efeito do aumento local do albedo sobre a temperatura do ar não chega a ser efetivo, sendo a redução de temperatura do ar induzida pelo uso de alto albedo insuficiente para promover uma melhora no conforto térmico no plano do pedestre. O piso, no interior de cânions com a razão de aspecto aqui estudada $(\mathrm{H} / \mathrm{W}=1)$, não é uma superfície onde a aplicação de acabamentos de alto albedo seja recomendável, por aumentar o estresse térmico no plano do pedestre, podendo também criar situações de ofuscamento visual de pedestres e motoristas.

Figura 7 - Total líquido de estresse térmico e níveis de conforto/desconforto para Maringá, PR (ZB 1)

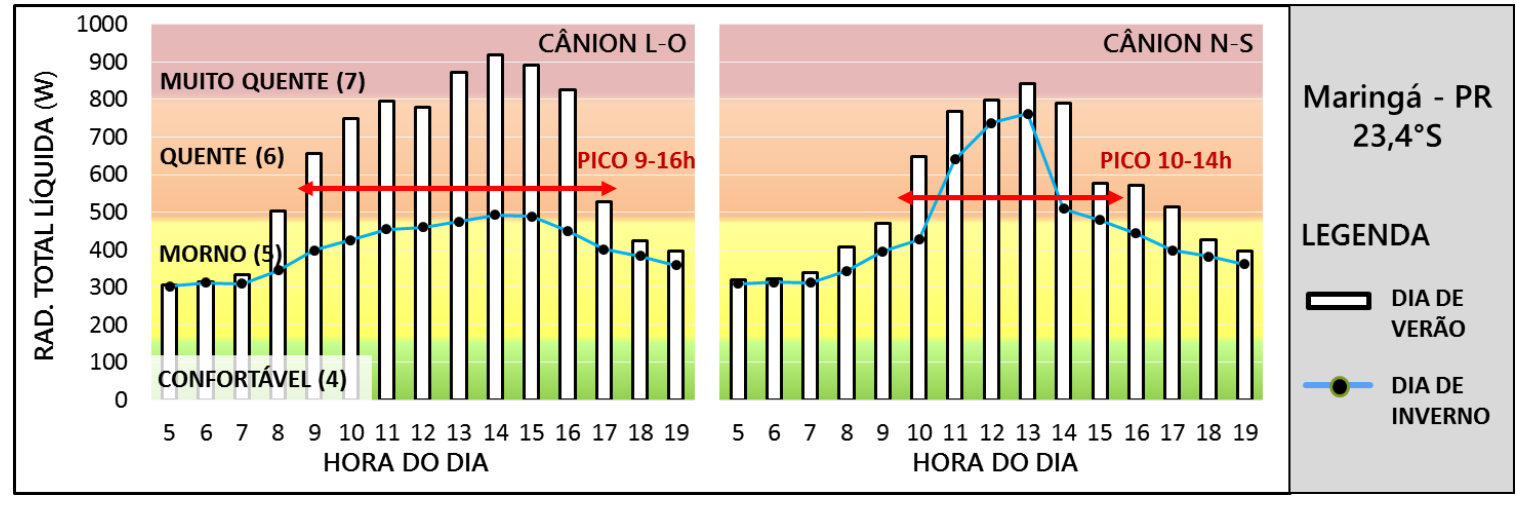

102 Krüger, E. L.; Gonzalez, D. E. G. 
Figura 8 - Níveis de conforto do pedestre para todos os cenários

\begin{tabular}{|c|c|c|c|c|c|c|c|c|c|c|c|c|c|c|c|c|c|c|c|c|c|c|c|c|c|c|c|c|c|c|c|c|}
\hline \multirow{4}{*}{ 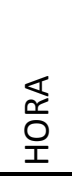 } & \multicolumn{32}{|c|}{ ITS - Nível de Conforto do Pedestre (DIA DE VERÃO) } \\
\hline & \multicolumn{4}{|c|}{ ZB 1} & \multicolumn{4}{|c|}{ ZB 2} & \multicolumn{4}{|c|}{\begin{tabular}{l|l} 
ZB 3 &
\end{tabular}} & \multicolumn{4}{|c|}{ ZB 4} & \multicolumn{4}{|c|}{ ZB 5} & \multicolumn{4}{|c|}{ ZB 6} & \multicolumn{4}{|c|}{ ZB 7} & \multicolumn{4}{|c|}{ ZB 8} \\
\hline & \multicolumn{2}{|c|}{$\leftrightarrow$} & \multicolumn{2}{|c|}{$\uparrow$} & \multicolumn{2}{|c|}{$\leftrightarrow$} & \multicolumn{2}{|c|}{$\uparrow$} & \multicolumn{2}{|c|}{$\leftrightarrow$} & 1 & & $\leftarrow$ & & $\uparrow$ & & & & & & & & & t & & & & & $\leftarrow$ & & $\uparrow$ & \\
\hline & - & O & - & O & - & 0 & - & 0 & - & 0 & - & 0 & $\bullet$ & 0 & $\bullet$ & 0 & ㅇ & 0 & - & 0 & ㅇ & 0 & ○ & O & $\bullet$ & 0 & • & O & $\bullet$ & 0 & & 0 \\
\hline 6 & 5 & 5 & 5 & 5 & 5 & 5 & 5 & 5 & 5 & 5 & 5 & 5 & 5 & 5 & 5 & 5 & 5 & 5 & 5 & 5 & 5 & 5 & 5 & 5 & 5 & 5 & 5 & 5 & 5 & 5 & 5 & 5 \\
\hline 7 & 5 & 5 & 5 & 5 & 5 & 5 & 5 & 5 & 5 & 5 & 5 & 5 & 5 & 5 & 5 & 5 & 5 & 5 & 5 & 5 & 5 & 5 & 5 & 5 & 5 & 5 & 5 & 5 & 5 & 5 & 5 & 5 \\
\hline 8 & 6 & 6 & 5 & 5 & 5 & 5 & 5 & 5 & 6 & 6 & 5 & 5 & 6 & 6 & 5 & 5 & 6 & 6 & 5 & 5 & 5 & 5 & 5 & 5 & 6 & 6 & 5 & 5 & 6 & 6 & 6 & 6 \\
\hline 9 & 6 & 6 & 5 & 5 & 6 & 6 & 5 & 5 & 6 & 6 & 5 & 5 & 6 & 6 & 5 & 5 & 6 & 7 & 6 & 6 & 6 & 6 & 6 & 6 & 6 & 6 & 6 & 6 & 7 & 7 & 6 & 6 \\
\hline 10 & 6 & 6 & 6 & 6 & 6 & 6 & 6 & 6 & 6 & 6 & 6 & 6 & 6 & 6 & 6 & 6 & 7 & 7 & 6 & 6 & 6 & 6 & 6 & 6 & 6 & 6 & 6 & 6 & 7 & 7 & 6 & 6 \\
\hline 11 & 6 & 6 & 6 & 6 & 6 & 6 & 6 & 6 & 6 & 6 & 6 & 6 & 6 & 6 & 6 & 6 & 7 & 7 & 6 & 7 & 6 & 7 & 6 & 6 & 6 & 7 & 6 & 6 & 7 & 7 & 7 & 7 \\
\hline 12 & 6 & 6 & 6 & 6 & 6 & 6 & 6 & 6 & $\overline{6}$ & 6 & 6 & 6 & 6 & 6 & 6 & 6 & 6 & 7 & 6 & 7 & 6 & 6 & 6 & 6 & 6 & 6 & 6 & 6 & 7 & 7 & 6 & 7 \\
\hline 13 & 7 & 7 & 6 & 7 & 6 & 7 & 7 & 7 & 6 & 7 & 6 & 6 & 6 & 7 & 6 & 7 & 7 & 7 & 6 & 7 & 6 & 6 & 6 & 6 & 6 & 7 & 6 & 7 & 7 & 7 & 6 & 7 \\
\hline 14 & 7 & 7 & 6 & 6 & 7 & 7 & 6 & 7 & 7 & 7 & 6 & 6 & 6 & 6 & 6 & 6 & 6 & 7 & 6 & 6 & 7 & 7 & 6 & 7 & 7 & 7 & 6 & 6 & 7 & 7 & 6 & 6 \\
\hline 15 & 7 & 7 & 6 & 6 & 7 & 7 & 6 & 6 & 7 & 7 & 6 & 6 & 7 & 7 & 6 & 6 & 6 & 6 & 6 & 6 & 7 & 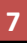 & 6 & 6 & 6 & 6 & 6 & 6 & 6 & & 6 & 6 \\
\hline 16 & 7 & 7 & 6 & 6 & 7 & 7 & 6 & 6 & 6 & 6 & 5 & 5 & 7 & 7 & 6 & 6 & 6 & 6 & 6 & 6 & 7 & 7 & 6 & 6 & 6 & 6 & 6 & 6 & 6 & 6 & 6 & 6 \\
\hline 17 & 6 & 6 & 6 & 6 & 6 & 6 & 6 & 6 & 5 & 5 & 5 & 5 & 5 & 6 & 5 & 6 & 5 & 5 & 5 & 5 & 6 & 6 & 6 & 6 & 6 & 6 & 6 & 6 & 5 & 6 & 6 & 6 \\
\hline 18 & 5 & 5 & 5 & 5 & 5 & 5 & 5 & 5 & 5 & 5 & 5 & 5 & 5 & 5 & 5 & 5 & 5 & 5 & 5 & 5 & 5 & 5 & 5 & 5 & 5 & 5 & 5 & 5 & 5 & 5 & 5 & 5 \\
\hline OTES & & & & & & & & & & & & & & & & & & & & & & & & & & & & & & & & \\
\hline & & $\mathrm{Mu}$ & ito & 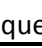 & nte & & & 6 & Que & $r$ & & & & & Mo & & & & & & & & & táv & & & & 3 & Fric & & & \\
\hline & & & & & & & & & 1 & & & & & & & & & & & & & 1 & & & & \llcorner & & & & & & \\
\hline & & $\mathrm{ZE}$ & & & & ZB & & & & ZB & & & & ZE & & & & ZE & & & & & & & & $\overline{\mathrm{ZE}}$ & & & & $\overline{Z B}$ & & \\
\hline 옥 & $\leftarrow$ & & & $\downarrow$ & $\leftarrow$ & & 1 & & $\leftarrow$ & & 1 & & $\leftarrow$ & & 1 & & & & & & & & & $\downarrow$ & & & & $\downarrow$ & $\leftarrow$ & & $\uparrow$ & \\
\hline 오 & - & 0 & - & 잉 & - & 0 & 0 & 0 & - & 0 & 0 & 이 & - & 0 & - & O & • & 0 & • & 0 & - & 0 & • & 0 & $\bullet$ & 0 & ○ & 0 & - & 0 & 0 & 0 \\
\hline 6 & 5 & 5 & 5 & 5 & 5 & 5 & 5 & 5 & 5 & 5 & 5 & 5 & 5 & 5 & 5 & 5 & 5 & 5 & 5 & 5 & 5 & 5 & 5 & 5 & 5 & 5 & 5 & 5 & 5 & 5 & 5 & 5 \\
\hline 7 & 5 & 5 & 5 & 5 & 5 & 5 & 5 & 5 & 5 & 5 & 5 & 5 & 5 & 5 & 5 & 5 & 5 & 5 & 5 & 5 & 5 & 5 & 5 & 5 & 5 & 5 & 5 & 5 & 5 & 5 & 5 & 5 \\
\hline 8 & 5 & 5 & 5 & 5 & 5 & 5 & 5 & 5 & 5 & 5 & 5 & 5 & 5 & 5 & 5 & 5 & 5 & 5 & 5 & 5 & 5 & 5 & 5 & 5 & 5 & 5 & 5 & 5 & 5 & 5 & 5 & 5 \\
\hline 9 & 5 & 5 & 5 & 5 & 5 & 5 & 5 & 5 & 5 & 5 & 5 & 5 & 5 & 5 & 5 & 5 & 5 & 5 & 5 & 5 & 5 & 5 & 5 & 5 & 5 & 5 & 5 & 5 & 5 & 5 & 5 & 5 \\
\hline 10 & 5 & 5 & 5 & 5 & 5 & 5 & 5 & 5 & 5 & 5 & 5 & 5 & 5 & 5 & 5 & 5 & 5 & 5 & 5 & 5 & 5 & 5 & 5 & 5 & 6 & 6 & 6 & 6 & 5 & 5 & 6 & 6 \\
\hline 11 & 5 & 5 & 6 & 6 & 5 & 5 & 5 & 6 & 5 & 5 & 6 & 6 & 5 & 5 & 6 & 6 & 5 & 5 & 6 & 6 & 5 & 5 & 6 & 6 & 6 & 6 & 6 & 6 & 5 & 6 & 6 & 6 \\
\hline 12 & 5 & 5 & 6 & 6 & 5 & 5 & 6 & 6 & 5 & 5 & 6 & 6 & 5 & 5 & 6 & 6 & 5 & 5 & 6 & 6 & 5 & 5 & 6 & 6 & 6 & 6 & 6 & 7 & 6 & 6 & 6 & 7 \\
\hline 13 & 5 & 5 & 6 & 6 & 5 & 5 & 6 & 6 & 5 & 5 & 6 & 6 & 5 & 6 & 6 & 6 & 5 & 6 & 6 & 6 & 5 & 5 & 6 & 6 & 6 & 6 & 6 & 7 & 6 & 6 & 6 & 6 \\
\hline 14 & 5 & 6 & 6 & 6 & 5 & 5 & 5 & 5 & 5 & 5 & 5 & 5 & 5 & 6 & 6 & 6 & 5 & 5 & 5 & 6 & 5 & 6 & 6 & 6 & 6 & 6 & 6 & 6 & 5 & 5 & 5 & 6 \\
\hline 15 & 6 & 6 & 5 & 5 & 5 & 5 & 5 & 5 & 5 & 5 & 5 & 5 & 5 & 6 & 5 & 6 & 5 & 5 & 5 & 5 & 6 & 6 & 6 & 6 & 6 & 6 & 6 & 6 & 5 & 5 & 5 & 5 \\
\hline 16 & 5 & 5 & 5 & 5 & 5 & 5 & 5 & 5 & 5 & 5 & 5 & 5 & 5 & 5 & 5 & 5 & 5 & 5 & 5 & 5 & 5 & 5 & 5 & 5 & 6 & 6 & 6 & 6 & 5 & 5 & 5 & 5 \\
\hline 17 & 5 & 5 & 5 & 5 & 5 & 5 & 5 & 5 & 5 & 5 & 5 & 5 & 5 & 5 & 5 & 5 & 5 & 5 & 5 & 5 & 5 & 5 & 5 & 5 & 5 & 5 & 5 & 5 & 5 & 5 & 5 & 5 \\
\hline 18 & 5 & 5 & 5 & 5 & 5 & 5 & 5 & 5 & 5 & 5 & 5 & & 5 & 5 & 5 & 5 & 5 & 5 & 5 & 5 & 5 & 5 & 5 & 5 & 5 & 5 & 5 & 5 & 5 & 5 & 5 & 5 \\
\hline
\end{tabular}

Quanto à orientação cardeal do eixo do cânion, cânions N-S representam uma condição de menor estresse térmico ao pedestre, por sua condição de maior sombreamento pela manhã e tarde, ficando esses expostos apenas nas horas centrais do dia. Cânions L-O, pelo contrário, apresentam maior variabilidade sazonal dos efeitos do albedo sobre os níveis de estresse térmico para o pedestre, ficando expostos à radiação solar direta durante todo o dia no verão, enquanto no inverno ficam mais sombreados que cânions N-S, especialmente em latitudes mais altas, onde o inverno é mais ameno e desejar-se-ia uma maior exposição solar. Ressalta-se que a orientação ideal de um cânion deve considerar também os padrões de vento locais.
Considerando possíveis benefícios térmicos na situação de inverno, como no caso da ZB1, verificou-se que os prejuízos decorrentes do aumento da radiação refletida com a piora das condições de conforto térmico no plano do pedestre durante o verão não trazem, em contrapartida, benefícios significativos no inverno. Tais resultados confirmam observações realizadas por Erell et al. (2014), em pesquisa semelhante com o modelo CAT empregado neste trabalho.

Como limitações do estudo, ressaltam-se as seguintes:

(a) assume-se que o CAT seja aplicável ao clima das cidades analisadas; 
(b) assume-se que o ITS seja aplicável ao clima das cidades analisadas e à faixa de conforto de cada população (uma vez que não houve calibração do ITS para cada cidade - aponta-se para a importância de estudos de campo em conforto em espaços abertos em cidades brasileiras);

(c) trata-se de um estudo teórico, sem que tenha sido feita uma calibração do modelo a situações térmicas reais nas cidades e condições analisadas;

(d) o fato de as condições de conforto e desconforto estudadas no plano do pedestre considerarem seu posicionamento no centro da via. Uma vez que a posição mais comum é junto às calçadas, onde as condições de sombreamento mudam, seria interessante para trabalhos futuros que se desenvolvessem os cálculos para essa condição; e

(e) foram analisadas apenas uma razão de aspecto (fator H/W) e duas orientações do eixo do cânion. $\mathrm{O}$ estudo poderia ser estendido para outras morfologias de cânion, mostrando de forma mais detalhada os limites de utilização de AA para a melhoria das condições térmicas no interior do cânion.

\section{Referências}

\section{ASSOCIAÇÃO BRASILEIRA DE NORMAS} TÉCNICAS. NBR 15220-1: desempenho térmico de edificações: parte 1: definiçõos, símbolos e unidades. Rio de Janeiro, 2005a.

\section{ASSOCIAÇÃO BRASILEIRA DE NORMAS TÉCNICAS. NBR 15220-2: desempenho térmico de edificações: parte 2: métodos de cálculo da transmitância térmica, da capacidade térmica, do atraso térmico e do fator solar de elementos e componentes de edificações. Rio de Janeiro,} $2005 b$.

\section{ASSOCIAÇÃO BRASILEIRA DE NORMAS}

TÉCNICAS. NBR 15220-3: desempenho térmico de edificações: parte 3: zoneamento bioclimático brasileiro e estratégias de condicionamento térmico passivo para habitações de interesse social. Rio de Janeiro, 2005c.

\section{AMERICAN SOCIETY FOR TESTING AND} MATERIALS. ASTM STP 900: performance of protective clothing. Pennsylvania, 1986.

BROWN, G. Z.; DEKAY, M. Sol, Vento e Luz: estratégias para o projeto de arquitetura. 2. ed. Porto Alegre: Bookman, 2004.
CAMUFFO, D.; BERNARDI, A. An

Observational Study of Heat Fluxes and Their Relationships With Net Radiation. BoundaryLayer Meteorology, v. 23, n. 3, p. 359-368, 1982.

CARNIELO, E.; ZINZI, M. Optical and Thermal Characterisation of Cool Asphalts to Mitigate Urban Temperatures and Building Cooling Demand. Building and Environment, v. 60, p. 56-65, 2013.

EMMANUEL, R.; FERNANDO, H. J. S. Urban Heat Island in Humid and Arid Climates: role of urban form and thermal properties in Colombo, Sri Lanka and Phoenix, USA. Climate Research, v. 34, n. 3, p. 241-251, 2007.

ERELL, E. et al. The Effect of Stabillity on Estimated Variations of Advected Moisture in the Canyon Air Temperature (CAT) Model. In: AMS SYMPOSIUM ON THE URBAN ENVIRONMENT, 9., Keystone, 2010. Proceedings... Keystone: American Meteorological Society, 2010.

ERELL, E. et al. Effect of High-Albedo Materials on Pedestrian Heat Stress in Urban Street Canyons. Urban Climate, v. 10, n. 2, p. 367-386, 2014.

ERELL, E.; PEARLMUTTER, D.; WILLIAMSON, T. Urban Microclimate: designing the spaces between buildings. Washington: Earthscan, 2011.

ERELL, E.; WILLIAMSON, T. Simulating Air Temperature in an Urban Street Canyon in All Weather Conditions Using Measured Data at a Reference Meteorological Station. International Journal of Climatology, v. 26, p. 1671-1694, 2006.

GARTLAND, L. Ilhas de Calor: como mitigar zonas de calor em áreas urbanas. São Paulo: Oficina de Textos, 2010.

GIVONI, B. Estimation of the Effect of Climate on Man: development of a new thermal index. PhD Thesis, Technion - Israel Institute of Technology, Haifa, Israel, 1963.

GOOGLE. Google Earth. Versão 7.1.5. [Imagem]. Google Inc. Disponível em:

<http://www.google.com.br/intl/pt-BR/earth/>. Acesso em: 2014a.

GOOGLE. Google Maps. [Imagem]. Google Inc. Disponível em:

<https://www.google.com.br/maps/>. Acesso em: 2014b. 
GRIMMOND, C. S. B.; OKE, T. R. Aerodynamic Properties of an Urban Area Derived From Analysis of Surface Form. Journal of Applied Meteorology, v. 38, n. 9, p. 1262-1292, 1999.

GRIMMOND, C. S. B.; OKE, T. R. Turbulent Heat Fluxes in Urban Areas: observations and a local-scale urban meteorological parameterization scheme (LUMPS). Journal of Applied

Meteorology, v. 41, n. 7, p. 792-810, jul. 2002.

INSTITUTO BRASILEIRO DE GEOGRAFIA E ESTATÍSTICA. Censo 2010. Disponível em: <http://www.censo2010.ibge.gov.br>. Acesso em: 15 ago. 2012.

JACOBSON, M. Z.; TEN HOEVE, J. E. Effects of Urban Surfaces and White Roofs on Global and Regional Climate. Journal of Climate, v. 25, n. 3, p. 1028-1044, 2012.

KOTTEK, M. et al. World Map of the KöppenGeiger Climate Classification Updated.

Meteorologische Zeitschrift, v. 15, n. 3, p. 259263, 2006.

LAND PROCESSES DISTRIBUTED ACTIVE ARCHIVE CENTER. Landsat 8 Imagery. Sioux Falls: LP DAAC, 2013. Disponivel em: <http://earthexplorer.usgs.gov/>. Acesso em: 2014.

MONTEITH, J.; UNSWORTH, M. Principles of Environmental Physics. 4. ed. London: Academic Press, 2013.

NATIONAL OCEANIC AND ATMOSPHERIC ADMINISTRATION. Solar Calculations

Spreadsheets. Disponível em: <http://www.esrl.noaa.gov/gmd/grad/solcalc/calcd etails.html>. Acesso em: 25 ago. 2014.

OKE, T. R. Boundary Layer Climates. London: Routledge, 2002.

PEARLMUTTER, D. Watts in a Comfort Index: evaluating pedestrian energy exchange and thermal stress in urban environments. In:

INTERNATIONAL CONFERENCE ON URBAN CLIMATE, 9.; SYMPOSIUM ON THE URBAN ENVIRONMENT, 12., Toulouse, 2015.

Proceedings... Toulouse, 2015.
PEARLMUTTER, D.; BERLINER, P.; SHAVIV, E. Integrated Modeling of Pedestrian Energy Exchange and Thermal Comfort in Urban Street Canyons. Building and Environment, v. 42, n. 6, p. 2396-2409, 2007.

PEARLMUTTER, D.; JIAO, D.; GARB, Y. The Relationship Between Bioclimatic Thermal Stress and Subjective Thermal Sensation in Pedestrian Spaces. International Journal of

Biometeorology, v. 58, p. 2111-2127, mar. 2014.

RORIZ BIOCLIMÁTICA: CONFORTO TÉRMICO E EFICIÊNCIA ENERGÉTICA. Base de Dados Climáticos de 411 Municípios Brasileiros. 2012. Disponivel em: <http://www.roriz.eng.br/epw_9.html>. Acesso em: 12 abr. 2012.

SAILOR, D. J. et al. Building Energy Use Implications of Ground-Level Albedo Modification. In: INTERNATIONAL CONFERENCE ON URBAN CLIMATE, 8., Dublin, 2012. Proceedings... 2012.

SHASHUA-BAR, L.; TSIROS, I.; HOFFMAN, M. Passive Cooling Design Options to Ameliorate Thermal Comfort in Urban Streets. Building and Environment, v. 57, p. 110-119, 2012.

SYNNEFA, A.; SANTAMOURIS, M.; LIVADA, I. A Study of the Thermal Performance of Reflective Coatings. Solar Energy, v. 80, n. 8, p. 968-981, 2006.

TAHA, H. et al. Residential Cooling Loads and the Urban Heat Island: the effects of albedo. Building and Environment, v. 23, p. 271-283, 1988.

YAGHOOBIAN, N.; KLEISSL, J. Effect of Reflective Pavements on Building Energy Use. Urban Climate, v. 2, p. 25-42, dez. 2012.

\section{Agradecimentos}

Agradecimentos especiais ao Prof. Evyatar Erell, autor do modelo teórico utilizado na pesquisa, que supervisionou a pesquisa durante período de seis meses da co-autora junto ao Blaustein Institute for Desert Research (BIDR), no Campus de SedeBoqer da Ben-Gurion University of the Negev (BGU), Israel. 


\section{Eduardo Leite Krüger}

Programa de Pós Graduação em Tecnologia | Universidade Tecnológica Federal do Paraná | Av. Sete de Setembro, 3165, Rebouças |

Curitiba - PR - Brasil | CEP 80230-901 | Tel.: (41) 3310-4725 Ramal 4725 | E-mail: ekruger@utfpr.edu.br

Dominique Elena Giordano Gonzalez

Curso Técnico em Edificacões | Instituto Federal de Educacão, Ciência e Tecnologia do Paraná | Av. Salgado Filho, 1474, Guabirotuba | Curitiba - PR - Brasil | CEP 81510-000 | Tel.: (41) 3535-1400 | E-mail: domi.giordano@gmail.com

\section{Revista Ambiente Construído}

Associação Nacional de Tecnologia do Ambiente Construído

Av. Osvaldo Aranha, $99-3^{\circ}$ andar, Centro

Porto Alegre - RS - Brasil

CEP 90035-190

Telefone: +55 (51) 3308-4084

Fax: +55 (51) 3308-4054

www.seer.ufrgs.br/ambienteconstruido

E-mail: ambienteconstruido@ufrgs.br

106 Krüger, E. L.; Gonzalez, D. E. G. 